\title{
Mediation instructions and word attributes in paired-associate learning'
}

\author{
ALLAN PAIVIO AND JOHN C. YUILLE \\ UNIVERSITY OF WESTERN ONTARIO
}

Ss learned a list of noun paired-associates in which half the pairs were high and half were low in either their rated capacity to evoke images (I) or their meaningfulness (m). One group was instructed to use verbal mediators, another images, and $a$ third, rote repetition to learn the pairs. While both word attributes were positively related to learning, I was clearly more effective than $m$. Recall was poorer for repetition Ss than for either of the groups given mediation instructions. Predicted interactions of word attributes and mediation set were not confirmed, possibly because $S$ s (according to postlearning reports) did not uniformly follow a given mediation set with all types of pairs.

The availability of nonverbal images and implicit verbal responses as potential mediators has recently been coordinated theoretically to the abstract-concrete dimension of word meaning (Paivio, 1966; Paivio, Yuille, \& Smythe, 1966; Yuille \& Paivio, in press). As a result of their association with concrete objects and events as well as words, concrete nouns presumably acquire a "capacity" to evoke both nonverbal images and words as associative reactions. Abstract terms, on the other hand, acquire their meaning largely in intraverbal contexts and consequently are effective stimuli only for verbal associates. Applied to paired-associate (PA) learning (Paivio et al, 1966), the theory was supported by the findings that Ss predominantly reported having used images to link nouns that are concrete and high in their independently-rated capacity to evoke imagery (I), and verbal mediators to link abstract, low I nouns, particularly if the latter also were relatively high in meaningfulness (1.e., m, Noble, 1952). Expectations concerning mediation and learning also recelved some support.

The theory was tested in the present study by varying item attributes and mediation instructions. The I value (and concreteness) of the members of pairs was varied In one PA list and $m$ was varied in another. Different groups were instructed to use verbal mediators, images, or rote repetition to learn the pairs. Main effects were predicted for both item attributes and mediation instructions. In addition, the variables were expected to interact. Imagery instructions should facilitate the learning of high I pairs, interfere with low I pairs, and have little or no differential effect as a function of $\mathbf{m}$. Conversely, verbal mediation instructions should be particularly facilitative with high $m$ pairs (cf., the assoclative-probability hypothesis, Underwood \& Schulz, 1960). Ss were also questioned about the learning strategies they actually used during learning. Uothed

Two PA lists of 16 pairs each were constructed from a pool of 925 nouns for which $I$, concreteness, and 30 sec. production $\mathrm{m}$ data were available (Paivio, Yuille, \& Madigan, 1967). One list (List I) included eight pairs in which the randomly-paired members were high I (mean $=6.31$ ) and eight pairs that were low I (mean = 2.91). ${ }^{2}$ The words were equated for $m$ and were of $A A$ or A frequency (Thorndike \& Lorge, 1944). A second list (List M) was similarly constructed to include eight high $m($ mean $=6.63)$ and elght low $m($ mean $=4.50)$ pairs, with $I$ controlled and frequencies of 1-37. Two further lists were created by "turning over" the pairs in the original Lists $I$ and $M$. In terms of standard score units based on the sample of 925 words, the high-low variation was equivalent for $I$ and $m$.

Two instructional sets were used to encourage mediation and a third, to inhibit mediation. The Imagery set asked $S$ to link each pair with a mental picture; the Verbal set, with a word or phrase. A third set, Repetition, asked $S$ to learn by repeating each pair a number of times. The instructions and accompanying examples were mimeographed. Tested in groups, $32 \mathrm{Ss}$ received the original List $I$, another 32 were presented its "turned over" version; two groups of 33 and 30 received the two Lists $M$. In each group $1 / 3$ of the Ss received the Imagery mediation set, $1 / 3$ the Verbal mediation set, and $1 / 3$ the Repetition set instruction sheets. Standard PA instructions (Paivio, 1965) were first presented via tape recorder. Ss were then asked to read the mediation instructions, and this was followed by four alternating study and recall trials with the taperecorded PA list. On recall trials, Ss wrote their responses on recording sheets. Finally, Ss completed the post-learning questionnaire, which described five possible learning strategies (Repetition, Verbal mediation, Imaginal mediation, Some other device, and None) followed by the 16 palrs of the PA list. $S$ was asked to indicate which of the methods he had used to learn each pair.

One hundred and twenty-seven male high school graduates applying for admission to the Canadian Armed Forces university training program served as Ss.

Table 1. Mean Total Recall Scores as a Function of Word Attribute, Attribute Level, and Mediation Set

\begin{tabular}{|c|c|c|c|c|}
\hline & \multirow{2}{*}{$\begin{array}{l}\text { Attribute } \\
\text { Level }\end{array}$} & \multicolumn{3}{|c|}{ Mediation Set } \\
\hline & & Imagery & Verbal & Repetition \\
\hline List I & $\begin{array}{l}\text { High I } \\
\text { Low I }\end{array}$ & $\begin{array}{l}6.21 \\
3.00\end{array}$ & $\begin{array}{l}6.48 \\
3.24\end{array}$ & $\begin{array}{l}4.90 \\
2.26\end{array}$ \\
\hline List M & $\begin{array}{l}\text { High m } \\
\text { Low m }\end{array}$ & $\begin{array}{l}3.82 \\
2.46\end{array}$ & $\begin{array}{l}2.94 \\
1.71\end{array}$ & $\begin{array}{l}2.66 \\
1.45\end{array}$ \\
\hline
\end{tabular}


Table 2. Mean Number of Pairs for Which Ss Reported Using Imagery, Verbal Mediation, and Repetition Strategies as a Function of Mediation Set, Word Attribute, and Attribute Level

\begin{tabular}{|c|c|c|c|c|}
\hline \multirow{2}{*}{$\begin{array}{c}\text { Mediation } \\
\text { Set }\end{array}$} & \multirow{2}{*}{$\begin{array}{l}\text { Pair Attribute } \\
\text { and Level }\end{array}$} & \multicolumn{3}{|c|}{ Reported Strategy } \\
\hline & & Imogery & Verbal & Repetition \\
\hline Imogery & $\begin{array}{l}\text { High I } \\
\text { Low I }\end{array}$ & $\begin{array}{l}6.56 \\
2.25\end{array}$ & $\begin{array}{r}.06 \\
1.25\end{array}$ & $\begin{array}{r}.56 \\
2.75\end{array}$ \\
\hline \multirow[t]{2}{*}{ Verbal } & High 1 & 3.19 & 3.63 & 1.00 \\
\hline & Low 1 & .81 & 4.38 & 1.75 \\
\hline \multirow[t]{2}{*}{ Repetition } & High 1 & 2.81 & .44 & 4.06 \\
\hline & Low I & .75 & .69 & 5.63 \\
\hline \multirow[t]{2}{*}{ Imagery } & High m & 4.50 & .75 & 1.89 \\
\hline & Low $m$ & 3.13 & 1.00 & 1.75 \\
\hline \multirow[t]{2}{*}{ Verbal } & High m & 1.81 & 3.75 & 1.50 \\
\hline & Low m & .63 & 2.56 & 2.94 \\
\hline \multirow[t]{2}{*}{ Repetition } & High m & 2.63 & .56 & 3.44 \\
\hline & Low m & 1.25 & .38 & 4.13 \\
\hline
\end{tabular}

\section{Results and Discussion}

Learning scores were comparable for the original and "turned over" lists and their data were pooled. Ss were randomly discarded to equate the Ns in each cell at 20. The mean total recall scores for each experimental condition appear in Table 1. An analysis of variance performed on these data included mediation set, list (I vs. M), attribute level, and trials as factors. (Least interesting theoretically, the trials effect will not be reported.) All of the main effects were significant. Repetition set Ss performed more poorly than Ss given the Imagery or Verbal sets $(F=5.92, d f=2 / 114, p<.05)$; recall was better for pairs that were high rather than low in either Ior $m(F=400.76, d f=1 / 114, p<.01)$; and List I was recalled better than List $M(F=50.33, d f=1 / 114, p<$ $.01)$. An interaction of list by attribute level $(F=67.46$, $\mathrm{d} f=1 / 114, p<.01)$ indicated that variation in $I$ had a stronger effect that equivalent variation in $\mathrm{m}$.

The predicted interactions involving mediation set were not obtained. Since these predictions hinged on the effectiveness of the mediation instructions, the negative finding could mean that the instructions were not consistently followed for all types of pairs. Data relevant to this interpretation are provided by the post-learning mediation reports. The mean number of pairs for which Ss reported using the Imagery, Verbal, and Repetition methods, for each experimental condition, are shown in Table $2 .{ }^{3}$ These data suggest complex effects involving list, attribute level, set, and type of reported mediator. An analysis of variance was performed to evaluate these interactions (main effects from this analysis are of little theoretical interest and will not be considered). An interaction of set by type of reported mediator $(F=30.93, \mathrm{df}=$ $4 / 180, p<.01$ ) indicates that Ss significantly reported following the given instructional set. However, Ss' strategies were also influenced by other factors. An interaction of type of reported mediator by attribute level $(F=$ mediators and repetition, imagery was reported more often for high, and less often for low, I or m pairs. A triple interaction of type of reported mediator by attribute level by list ( $F=9.45, \mathrm{df}=2 / 180, \mathrm{p}<.01$ ) indicates that imagery reports varied particularly with noun $I$, that repetition was most frequent with pairs low on either attribute, and that verbal mediation was least affected by attribute type and level. The effects of the three variables were further qualified by type of mediation set, as indicated by the significant four-way interaction $(F=2.53, \mathrm{df}=4 / 180, \mathrm{p}<.05)$.

The general import of the mediation data is that the instructions were not adhered to uniformly. This is particularly apparent in the case of Imagery instructions for List I, where Ss reported following the set for 6.56 out of a possible average of eight of the high I pairs, but did so for an average of only 2.25 low I pairs. Thus, the reported use of imagery was apparently determined more by item attributes than by the instructional set. The overall pattern of results for both imaginal and verbal mediators is, in fact, highly similar to that obtained without instructions to mediate by Paivio et al (1966). Apparently the instructions increased the probability that Ss would use a particular mediator but did not override the effects of item attributes. In this regard, as in the case of PA learning, I was a more potent variable than $\mathrm{m}$.

\section{References}

Noble, C. E. An analysis of meaning. Psychol. Rev., 1952, 59, 421-430.

Paivio, A. Abstractness, imagery, and meaningfulness in pairedassociate learning. J. verbal Learn. verbal Behav., 1965, 4 . 32-38.

Paivio, A. Latency of verbal associations and imagery to noun stimuli as a function of abstractness and generality. Canad. $J$. Psychol., 1966, 30, 378-387.

Paivio, A., Yuille, J. C., \& Madigan, S. Concreteness, imagery, and meaningfulness values for 925 nouns. Research Bulletin No. 35 , Department of Psychology, University of Western Ontario, 1967.

Paivio, A., Yuille, J. C., \&mythe, P. C. Stimulus and response abstractness, imagery, and meaningfulness, and reported mediators in paired-associate learning. Canad. J. Psychol., 1966, 20, 362-377.

Thomdike, E. L., \& Lorge, I. The teacher's word book of 30,000 words. New York: Bureau of Publications, Teachers College, 1944.

Underwood, B. J., \& Schulz, R. W. Meaningfulness and verbal learning. Chicago: Lippincott, 1960.

Yuille, J. C., \& Paivio, A. Latency of imaginal and verbal mediators as a function of stimulus and response concretenessimagery. J. exp. Psychol., in press.

\section{Notes}

1. This research was supported by grants to the first author from the National Research Council of Canada (Grant APA-87) and the University of Western Ontario Research Fund.

2. Rated concreteness and I covaried in List I.

3. The two other categories on the post-learning questionnaire, Some Other and None, were infrequently reported and were excluded from the analysis. 